\title{
On the Variability of Interlanguage
}

\author{
Lichao Song \\ Qingdao University of Science and Technology, China \\ Email: marysongzhang@yahoo.com.cn
}

\begin{abstract}
The study of second language acquisition involves many aspects, among which interlanguage is an important one. Research on interlanguage and its various characteristics may make a great difference in the study of second language acquisition. This paper tends to explore one of the characteristics of interlanguage, its variability, so as to study its role in second language acquisition.
\end{abstract}

Index Terms —interlanguage, variability, second language acquisition

\section{INTRODUCTION}

The concept of interlanguage has been highly influential in the study of second language acquisition since it was proposed by Selinker (1972) in his seminal research paper Interlanguage, which provided the theoretical framework for interpreting second language acquisition as a mentalistic process and for the empirical investigation of interlanguage. Since then, the study of interlanguage and various aspects of it has never stopped. Let us first look at the definitions and characteristics of interlanguage.

\section{INTERLANGUAGE}

\section{A. Definitions of Interlanguage}

The notion similar to "interlanguage" was first seen in The Significance of Learners' Errors (Corder, 1967) as "transitional competence" to describe foreign language learners' linguistic ability which did not match that of native speakers. Selinker (1969) introduced the word "interlanguage", which was adapted from Weinreich's term "interlingual" to refer to the language system that the foreign language learner created based on the data he had been exposed to. Nemser (1971) referred to the same phenomenon in his term "approximative system", stressing the successive approximation to the target language. Corder (1971) used the term "idiosyncratic dialect" to suggest that the learner's language is unique to a particular individual, and that the rules of the learner's language are peculiar to the language of that individual alone. Selinker (1972) coined the term "interlanguage" to refer to the systematic knowledge of language which is independent of both the learner's native language and the target language. The term has come to be used with different but related meanings:

(1) to refer to the series of interlocking systems, which Corder (1967) called the learner's "built-in syllabbus" (Ellis, 1985).

(2) to refer to the system that is observed at a single stage of development ("an interlanguage").

(3) to refer to particular L1/L2 combinations (for example, L1 French/L2 English v. L1 Japanese/L2 English).

Interlanguage is neither the system of the native language nor that of the target language, but instead falls between the two. It is a system based on the best attempt of learners to provide order and structure to the linguistic stimuli surrounding them. By a gradual process of trial and error and hypothesis testing, learners slowly succeed in establishing closer and closer approximations to the system used by native speakers of the language.

Thus, the concept of "interlanguage" might better be understood if it is regarded as a continuum between the native language and the target language. At any point along the continuum, the learners' language is systematic, and any difference may be explained by differences in their learning experience (Larsen Freeman and Michael, 1991).

\section{B. The Characteristics of Interlanguage}

In his research paper Interlanguage, Selinker (1972) presented three main characteristics of interlanguage.

The first one is permeability. As he stated, the second language learners' language system is permeable, in the sense that rules that constitute the learners' knowledge at any stage are not fixed, but are open to amendment. In many aspects, this is a general feature of native languages. All language systems are permeable. Interlanguage differs from other language systems only in the degree of permeability.

The second one is that interlanguage is dynamic, i.e., interlanguage is constantly changing. However, a learner's interlanguage does not jump from one stage to the next, but rather slowly revises the interim systems to adapt new hypotheses to the target language system. This takes place by introduction of a new rule, first in one context and then in another, and so on. A new rule spreads in the sense that its coverage gradually extends over a range of linguistic contexts. The process of constant revision and extension of rules is a feature of the inherent instability of interlanguage and its built-in propensity for change. 
The third one is that interlanguage is systematic. In spite of the instability of interlanguage, it is possible to detect the rule-based nature of the learner's interlanguage. The learner does not select accidentally from his store of interlanguage rules, but in predictable ways.

Apart from the above mentioned characteristics, variability is another characteristic that can not be neglected. At any one stage in his development, the learner operates according to the system of rules he has constructed up to that point. A crucial issue is why his performance is so variable. On one occasion he uses one rule, while on another he uses a different one.

It has been generally accepted that interlanguage is variable (Dickerson, 1975; Huebner, 1979). This variability is evident both synchronically and diachronically. Each learner's interlanguage contains alternative rules for performing the same function. As it has been mentioned, on some occasions, one rule is used; on others, a different rule. Also, in spite of the striking uniformity in the developmental profile of different learners, there are variations in the overall course of development that learners follow. Interlanguage constitutes an unstable system and is permeable to invasion by new linguistic forms; its dynamic quality is reflected in tremendous interlanguage variability and also in overlapping stages over development as one set of variable rules is revised in favor of another.

\section{VARIABILITY OF INTERLANGUAGE}

Variability refers to cases where a second language learner uses two or more linguistic variants to express a phenomenon, which has only one realization in the target language. For example, Ellis (1985) reports a learner of English as second language who uses two variants for expressing negation in contiguous chunks of speech: No look my card/ Don't look my card. In trying to explain the sources of such variability in second language acquisition, researchers have generally worked from an assumption, first elaborated in work by Labov (1972) on native speakers of English, that variability is a systematic function of factors like the degree of formality of the context of utterance and the nature of the surrounding linguistic context.

\section{A. Study of Interlanguage Variability}

Studies of interlanguage variability have typically focused on the phenomena in which second language learners vary. As mentioned above, Ellis (1985) cited the case of a Portuguese-speaking boy learning English who, while playing a game, produced the following utterances within the same stretch of speech: No look my card/ Don't look my card. Here the learner is varying between No and Don't as negators in a way which native speakers would not. Another example of interlanguage variability where native speakers would not vary is provided in a study by Dickerson (1974), who looked at a number of features of the English pronunciation of ten Japanese speakers on three tasks: reading a list of words, reading a dialogue and free speech. Taking just one of the phonological phenomena studied by Dickerson, prevocalic /r/, as in run, it was found that the accuracy of the subjects' pronunciation varied as a function of two factors: the nature of the task and the nature of the vowel sound following the $/ r$. The subjects were most native-like in reading the dialogue and least native-like in free speech. Furthermore, the pronunciation of $/ \mathrm{r} /$ was more native-like before mid vowels as in run, than before high vowels as in read.

Tarone (1982) has attempted to explain systematic variability by suggesting that second language learners have a series of overlapping mental grammars, which correspond to different contexts in which the second language is used. At one extreme learners have a grammar for informal or vernacular second language use (e.g. in spontaneous casual conversation). At the other extreme learners have a grammar for formal or careful use of the second language (e.g. in writing or classroom use of the second language). Between these extremes there are mental grammars for different levels of formality of use. Tarone refers to this set of overlapping styles as the interlanguage capability continuum. Learners acquire grammars on the continuum through exposure to the second language in contexts of different levels of formality.

An important element in Tarone's account is the idea that degrees of "attention to form" are what determine the particular grammar on the continuum which a second language learner accesses. The grammar for formal or careful speech requires the learner to pay a high degree of attention to form, whereas the grammar for producing casual or vernacular speech requires no attention to form. If this theory is correct, asking second language speakers to perform different tasks in the second language which requires different degrees of attention to form should produce variability.

\section{B. Types of Interlanguage Variability}

Language use is characterized by systematic and non-systematic variation (Ellis, 1982), so Ellis (1992) classifies interlanguage variability into different types. 


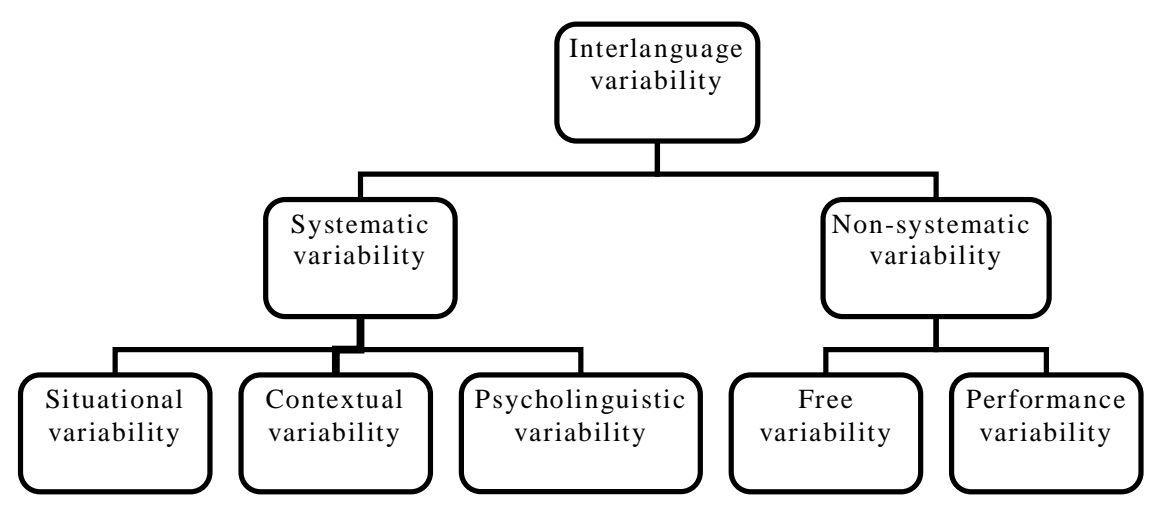

\section{Systematic variability}

Interlanguage is systematically variable, in the sense that although some of the variability observed is the result of relatively unpredictable factors regarding the state of mind and the emotional factors, other variability, particularly that deriving from the user's knowledge of how to use language appropriately, is systematic. In other words, at least part of the variability can be predicted and accounted for, as due to the effects of situational and linguistic contexts, psychological factors, etc. According to Ellis (1992), systematic variability can result from linguistic context, situational context and psychological context.

Linguistic context refers to the elements that precede and follow the variable structure in question. Variability in learner language that is induced by the effects of the linguistic contexts means that when the linguistic context changes, the learner's production of the target language also changes. The variability is evident at the phonological, morphological and syntactic levels of a language. Learners will make errors or mistakes in one type of sentence, but not in another type of sentence. When the linguistic context changes, the interlanguage also changes.

Situational context covers a whole host of factors. When any of the situational factors changes, the learner's performance will change. For example, when a learner is asked to answer the teacher's question in class, he will make mistakes which he will never make in grammar tests, for he is in urgent situation and has no time to make full use of his linguistic knowledge. Tarone suggests a style-continuum ranging from the vernacular style to the careful style in accordance with the demands of the situation. In the early stage of the stylistic study, it assumed that the careful style had been more correct, target-like variants than the vernacular style. However, some research by Beebe (1981) proved that learners do not always manifest the target-like variant in careful language use. The explanation for this may be that a learner's production is influenced by his first language or the awareness of his own identity, etc. Style-shifting is a complex process, and a learner's production of the target language is shifted by different style required. A number of factors influenced the styles, such as the learner's first language, the learner's stage of development, the difficulty of the target language feature, the social situation in question, whether the learner is sensitive to the social factors, etc. Style-shifting is designed to study interlanguage from the social linguistic aspect, and it explains to a certain extent why the learner's production of the target language varies according to different situations.

Psychological context refers to the extent to which the type of language use affords time for planning and encourages or discourages monitoring. In a psycholinguistic study, Hulstijn (1984) investigated the effects of time pressure, focus of attention and metalingual knowledge on accuracy. The results indicated that neither metalingual knowledge nor time pressure had an effect on accuracy, but time pressure did influence the other two aspects of the learner's performance, response duration and speech rate. If the learners use the planning time to focus on the linguistic forms, increased accuracy will result. But if they use the time to plan and organize informational content, accuracy is less likely to achieve. Thus in a given task, if time requirement is a variable, it can serve as one element in interpreting the various language production of the learners.

The study of the linguistic context, situational context and psycholinguistic context suggest that interlanguage can be a systematic whole, though it has a great number of unforeseeable factors.

2. Non-systematic variability

Interlanguage is also characterized by non-systematic variability, which is of two types: performance variability and free variability.

Performance variability is the result of some failure of performance, including slips of tongue, false starts, derivation from rules, changes of mind and so on. Hochett (1948) refers to these as lapses. They may be the effect of the learner's psychological and emotional factors. According to Chomsky (1965), this type of variability is not part of the language user's competence. It occurs when the language user is unable to perform his competence. A typical example in English would be: "That is the problem which I don't know how to solve it" (Reibel, 1969). Sentences like this are normally readily correctable by the speaker himself. However, not all non-systematic variability is of this type. It is of great interest for understanding second language acquisition.

Free variability refers to the phenomenon that the learner possesses two or more forms, which he uses to realize the same range of meanings. It is the result of competing rules in the learner's competence. It is not difficult to find examples of free variability, although the examples are likely to be idiosyncratic. For example, native speakers may use 
pairs like /iy/ and /ay/ for either, who and that in restrictive relative clause. However, in native-speaker speech, such free variability is limited. Interlanguage, in contrast, is marked by a high level of free variability, a characteristic that is important for explaining how interlanguage evolves.

\section{The Role of Interlanguage Variability in Second Language Acquisition}

From the point of view of systematic variability, Tarone (1983) argues that one way, in which second language acquisition can proceed, is by forms which are initially part of the learner's careful style to spread to his vernacular style. It has been noted that the careful interlanguage style contains more target language forms than the vernacular style. Development does not consist of sudden jumps, but of the gradual extension of regularities from formal to progressively informal styles on the one hand, and from simple to increasingly complex linguistic contexts on the other. In this sense, second language acquisition involves a gradual reduction in the degree of variability as non-target language variants are eliminated in a steadily growing range of environments.

Ellis (1985) is especially impressed by the high degree of free variation in interlanguage. In his opinion, second language acquisition involves two stages: the assimilation of new forms and the sorting-out of form-function correlations. Assimilation results from the learner's being "open" to forms occurring in the input and operating on these by means of one or more interlanguage strategies. Then the learner forms an initial hypothesis regarding the target language rules. Irrespective of whether correspondence does or does not exist, new forms will continue to be assimilated until in two or more forms being used in free variation. Unless alternative forms can be justified by allocating them to different functions, redundant forms will be eliminated from the interlanguage. The learner will try to maximize his linguistic resources by creating a system in which different forms serve different functions. The first stage consists of forms used in free variation, but subsequent stages involve the progressive sorting of forms in to functional pigeon holes. It is likely that the first sorting out will not establish the form-function correlations of the target language. This may take several sortings, and many learners may never fully achieve it. The sorting process is a continuous one as long as new forms are assimilated, as each new form will require further functional reorganization in order to resolve the attendant free variability.

Therefore, it is not difficult to see why two types of variability arise in interlanguage. Non-systematic variation occurs when new forms are assimilated but have not yet been integrated into the learner's form-function system. Systematic variation occurs when the new forms have been accommodated by the existing form-function system.

\section{IMPLiCATION TO LANGUAGE TEACHING}

The aim of studying interlanguage variability is to explore the natural rule of language learning to provide theoretical basis and implications for classroom instruction, choices and arrangements of teaching materials. The factors that influence the changes of interlanguage may have an essential impact on language teaching. In fact, interlanguage variability is rule-governed, systematic, but its varieties also prove that this system can be changed by employing different teaching methods, creating different linguistic contexts and social contexts which can either facilitate language teaching or hinder language teaching conversely. Based on the research, language teachers and researchers are required to make a close study of the factors resulting in variability of interlanguage in order to take the language teaching tasks into moderate control. As the students vary from each other in many aspects, the study of variability turns out to be very tedious and demanding. One thing that should be mentioned is that the study of variability itself is not important, while what is important is how to make sufficient use of the study results to guide language teaching and research in practice, such as causing thorough changes in the teachers' attitude, resulting in making good use of the factors to improve the quality of language teaching and research. So far, some tentative conclusions have been drawn. The more language teachers are aware of the variability of interlanguage and its various factors, the more they may be conscious of its importance and thus may be efficient in their teaching practice, and the better they can make use of the conclusions of the study.

The study of interlanguage variability makes teachers who always see the incorrect productions by the learners in the bad light more tolerant of errors and more acceptable of errors, and this can be seen as a breakthrough in language teachers' attitude. Over-criticizing students when they make mistakes can only result in the students' losing interests, low motivation, and repulsion, etc, reducing their chances of achievement. Many teachers have discovered that some active language learners employ hypothesis testing to gain the recognition of the target language, but passive learners are more likely to refrain from learning, and given more time, a learner is likely to perform better.

When it comes to judging students' achievement of learning target languages, many factors should be taken into consideration, for example, the students' social and psychological, emotional, strategical factors. Some psycholinguists also illustrate that sometimes something wrong happens to the utterance only because the prescribed time is limited, or the speaker is too excited, or too angry, or they lack noticing or attention to what he is saying, or the speaker simply thinks that it is unnecessary for him to correct the previous mistakes. Be the errors in written form or in oral form, there will always be some psycholinguistic elements in them. As an internal factor in language production, psycholinguistic elements are likely to be influenced by various external factors, so while teaching the second language, language teachers should stick to the hypothesis of teachability (to teach what is teachable at a very suitable stage, not too hard, nor too easy), and input in the students the ideas of learning what is learnable according the hypothesis of learnability. 
Learning or teaching too hard materials can only make the learners feel frustrated, upset and uneasy. To prevent the students from forming some negative psychological complex, teachers should be very careful when preparing the syllabus, organizing the activities, after-class curriculum, etc. The learner's attitude, emotion, motivation, personality, etc. which influence learning are called affective variables, and more people like to treat them in a more broader sense as psychological factors. They are invisible, too abstract to detect, but proper controls over them are possible by way of adjusting teaching methods. The affective variables change, so does interlanguage.

A point that interlanguage variability challenges the traditional teaching is that interlanguage encourages the teachers to use as much the target language as possible. As interlanguage changes quickly and naturally, the more the learners are exposed to the interlingual situation, the more quickly interlanguage will change and progress to the target language. The exposure to correct forms of a target language provides the students with a bridge get to the target language and consolidate the correct forms, abandoning the incorrect forms. This converges with Input Hypothesis of Krashen at the juncture that the more input of correct language forms, the better the learners will be at producing the target language. The realization of it further results in the elimination of traditional reading-traslation teaching method and the decrease of fixed, limited pattern drill models in foreign language textbooks, on the other hand, more and more communicative activities are being supplied to encourage the students to be more productive in their second language.

In fact, the attitudinal changes that interlanguage has to language teaching can be of the most elementary importance. In a broad sense, applied linguistica refers to the subject which studies the relationship between linguistics and other subjects, but here applied linguistics mainly refers to language teaching in the narrow sense, so it interwines closely with many other branches of study concerning language teaching, such as language testing which is one of the most essential subject. Interlanguage theory explains to the teachers and researchers why it is impossible for the learners to have the perfect mastery of the pronunciations, morphemes, intonations, etc. at the very beginning of learning in most cases, for the learners are likely to relate the target language to their native language, resulting in mistakes in every aspect. The expanantion makes it possible for the teachers to evaluate the students' progress in a more scientific and tolerable manner; this also makes the teachers understand that: to cover the distance between first language and second language, it takes time; and the theory makes the teachers look at the students' varieties of mistaken linguistic forms with an eye for improvement.

\section{CONCLUSION}

Second language acquisition is a creative construction, during which the learners are consciously or unconsciously constructing a language system which enable them to understand and produce utterances in the target language. This interlanguage system is flexible, dynamic and approximative. Learners are processing language on the basis of their own interlanguage, a system lying between the native language and the target language. Second language acquisition involves a series of evolving systems which comprise the interlanguage continuum. Each system is considered to be initially consistent and rule-governed.

Like all natural languages, interlanguage is variable. This variability is both systematic and non-systematic. Systematic variability is determined by both the linguistic and the situational contexts. Learners systematically vary their choice of interlanguage forms according to whether they require a vernacular style in unplanned discourse or a careful style in planned discourse. Their choice of forms is also influenced by the nature of linguistic environment. The key to this pattern of variation is the extent to which the learner monitors his own language. Heavy monitoring is likely to result in the learner's careful style; whereas, a low level of monitoring will result in the vernacular style, which is more natural and more systematic.Non-systematic variability is also common in second language acquisition. It is of great importance to the study of second language acquisition.

Findings like these provide some insights into the study of second language acquisition, revealing the way form-function relationships in interlanguage evolving over time. Nonetheless, such findings are far from enough. This is only a starting point. To do research in second language acquisition, we still have a long way to go.

\section{REFERENCES}

[1] Corder S.P. (1967). The Significance of Learner's Errors. IRAL, 5, 161-170

[2] Corder S.P. (1971). Idiosyncratic Dialects and Error Analysis. IRAL, 9, 147-159

[3] Dickerson. (1975). Interlanguage as a System of Variable Rules. TESOL, quarterly, 9, 4:401-407

[4] Ellis Rod. (1985). Understanding Second Language Acquisition. Oxford: Oxford University Press.

[5] Ellis Rod. (1985). Sources of variability in interlanguage. Applied Linguistics, 6, 2:118-131

[6] Ellis Rod. (1992). Learning to Communicate in the Classroom: a Study of Two Learners' Re-quest. Studies in Second Language Acquisition, 14, 1-23

[7] Ellis Rod. (1994). Second Language Acquisition. Oxford: Oxford University Press

[8] Hulstijn J. and Hulstijn W. (1984). Grammatical Errors as a Function of Processing Constraints and Explicit Knowledge. Language Learning, 34, 23-43

[9] Labov William. (1972). Socioloinguistic Patterns. Philadelphia: University of Pennsylvania Press.

[10] Larsen-Freeman and Michael H. Long. (1991). An introduction to second language acquisition research. New York: Longman

[11] Nemser W. (1971). Approximative Systems of Foreign Language Learners. International Journal of Applied Linguistics, 92, $115-123$ 
[12] Selinker L. (1972). Interlanguage. International Review of Applied Linguistics, 10, 209-241

[13] Selinker L. (1992). Rediscovering Interlanguage. Longman, London

[14] Tarone E. (1983). On the Variability of Interlanguage Systems. Applied Linguistics, 15, 285-295

[15] Tarone E. (1985). Variability in Interlanguage Use: a Study of Style-shifting in Morphology and Syntax. Language Learning, $35,373-403$

Lichao Song was born in Weihai, China in 1979. She received her Bachelor's degree in English from Qingdao Institute of Chemical Technology, China in 2000.

She is currently a lecturer in the College of Foreign Languages, Qingdao University of Science and Technology, Qingdao, China. At the same time, she is studying for her master's degree in the College of Foreign Languages, Qingdao University of Science and Technology, Qingdao, China. Her research interest is second language acquisition. 